DOI:10.2151/jmsj.87.865

\title{
Characteristics of Polarimetric Radar Variables in Three Types of Rainfalls in a Baiu Front Event over the East China Sea
}

\author{
Yukari SHUSSE, Katsuhiro NAKAGAWA \\ Okinawa Subtropical Environment Remote-Sensing Center, National Institute of Information and Communications
} Technology, Kunigami, Japan

Nobuhiro TAKAHASHI

National Institute of Information and Communications Technology, Koganei, Japan

Shinsuke SATOH

Okinawa Subtropical Environment Remote-Sensing Center, National Institute of Information and Communications Technology, Kunigami, Japan

and

Toshio IGUCHI

National Institute of Information and Communications Technology, Koganei, Japan

(Manuscript received 5 December 2008, in final form 25 June 2009)

\begin{abstract}
Characteristics of polarimetric radar variables in three rainfall types in a Baiu front event over the East China Sea observed on 1 June 2004 were studied and compared using a C-band polarimetric radar, the CRL Okinawa bistatic polarimetric radar (COBRA). The selected rainfalls are common types in the Baiu season in this area: (1) stratiform type (ST), (2) isolated convective type (ICT) and (3) embedded convective type (ECT). ST was characterized by an obvious bright band in the field of radar reflectivity $\left(Z_{\mathrm{hh}}\right)$. ICT and ECT had almost the same $30-\mathrm{dBZ}$ echo-top height of about $5.5 \mathrm{~km}$, and their strong echo region $\left(Z_{\mathrm{hh}}>40 \mathrm{dBZ}\right)$ did not exceed the $0^{\circ} \mathrm{C}$ level (4.4 $\mathrm{km}$ altitude) even in their mature stages.

Around the $0^{\circ} \mathrm{C}$ level, overall decrease in correlation coefficient between horizontal and vertical polarization signals $\left(\rho_{\mathrm{hv}}\right)$ and increase in differential reflectivity $\left(Z_{\mathrm{dr}}\right)$ were observed in ST and ECT, which indicated the presence of a layer of mixed-phase precipitation. By contrast, significant decrease in $\rho_{\mathrm{hv}}$ and increase in $Z_{\mathrm{dr}}$ were not found in ICT. At lower levels, $Z_{\mathrm{dr}}$ ranged from 0 to $1.5 \mathrm{~dB}$ and most of $\rho_{\mathrm{hv}}$ were higher than 0.98 in ST and ECT. The values of $Z_{\mathrm{dr}}$ and $\rho_{\mathrm{hv}}$ had wider variations in ICT. The characteristics of the vertical profiles of $Z_{\mathrm{dr}}$ and $\rho_{\mathrm{hv}}$ in ECT are consequently more similar to those in ST rather than to those in ICT, although their echo-top heights of $30 \mathrm{dBZ}$ and maximum $Z_{\mathrm{hh}}$ near the surface were almost equal.
\end{abstract}

Corresponding author and current affiliation: Yukari Shusse, Hydrospheric Atmospheric Research Center, Nagoya University, Furo-cho, Chikusa-ku, Nagoya, 464-8601, Japan.

E-mail: shusse@rain.hyarc.nagoya-u.ac.jp

(C) 2009, Meteorological Society of Japan 
Near the surface, sufficiently below the $0^{\circ} \mathrm{C}$ level, ICT had larger $Z_{\mathrm{dr}}$ and lower $\rho_{\mathrm{hv}}$ than ECT in the region with $Z_{\mathrm{hh}}$ stronger than $45 \mathrm{dBZ}$. This indicates that larger raindrops were more dominant in ICT than in ECT at the same $Z_{\mathrm{hh}}$ in the intense rainfall regions. This difference of dominant raindrop sizes appears to reflect the difference in precipitation growth processes between ICT and ECT.

\section{Introduction}

Improvements of precipitation physical models related to raindrop size distribution (DSD) and to hydrometeor information around and above the $0^{\circ} \mathrm{C}$ level are desired to upgrade rain-retrieval algorithms for spaceborne radars and microwave radiometers (e.g., Tropical Rainfall Measuring Mission (TRMM) and Global Precipitation Measurement (GPM)). An appropriate classification of rainfall types to select DSD and melting layer models is an equally important issue in terms of their practical use. For example, two DSD models were assumed to correspond to stratiform and convective types of precipitation in the TRMM 2A25 algorithm (Iguchi et al. 2000).

Several methods of classifying rainfall types mainly into convective and stratiform categories have been developed using ground-based instruments to characterize rain systems (e.g., Churchill and Houze 1984; Steiner et al. 1995; Rosenfeld et al. 1995; Williams et al. 1995; Tokay et al. 1999). For example, Steiner et al. (1995) proposed a method of convective-stratiform separation using horizontal distributions of radar reflectivity. The peaks in radar reflectivity indicated the centers of convective regions. Rosenfeld et al. (1995) presented a method using the bright band (BB) signature in stratiform regions to characterize rainfall types. However, it has been difficult to characterize the various rainfall systems from the perspective of cloud microphysics by conventional radar measurements. It is also difficult to obtain information about melting layers in convective rainfalls which are usually not accompanied by BB signatures.

Polarimetric radar observation is useful for obtaining the three-dimensional distribution of microphysical properties in precipitation clouds (e.g., Bringi and Chandrasekar 2001). For example, differential reflectivity $\left(Z_{\mathrm{dr}}\right)$ is useful for comparing the dominant drop sizes between precipitation areas. The correlation coefficient between horizontal and vertical polarization signals $\left(\rho_{\mathrm{hv}}\right)$ is sensitive to the existence of large wet particles such as melting aggregated snow.

During the rainy season in East Asia, which is called the Baiu season in Japan, relatively shallow convective rainfalls with $15-\mathrm{dBZ}$ echo top not more than $8 \mathrm{~km}$ are often observed and make large contributions to the amount of rainfall as reported by Zhang et al. (2006) and Chen et al. (2003). However, little is known about the characteristics of polarization signatures in the rainfall systems in this region, mainly due to the lack of polarimetric radar measurements.

Intensive field observation of subtropical rainfall was carried out in Okinawa, Japan, in May and June 2004 as part of the Global Satellite Mapping of Precipitation/Core Research for Evolutional Science and Technology (GSMaP/CREST) program. A C-band polarimetric radar, the CRL (Communications Research Laboratory), the forerunner of National Institute of Information and Communications Technology (NICT), Okinawa bistatic polarimetric radar (COBRA), was one of the main ground-based instruments operated in the observation. Good descriptions of COBRA are provided by Nakagawa et al. (2003) and Bringi et al. (2006). Bringi et al. (2006) conducted an intercomparison of rainfall parameters using COBRA, a 2D-video disdrometer and a $400 \mathrm{MHz}$ profiler for a Baiu front event during this observation period, which was composed of heavy convective rainfalls embedded in large areas of stratiform rain. They showed that the radar rainfall retrievals by COBRA were in good agreement with the 2D-video disdrometer for the entire period of the analysis.

In this study, three ordinary types of rainfalls in a Baiu event observed by COBRA during the observation period are selected for analysis: (1) stratiform type (ST), (2) isolated convective type (ICT) and (3) embedded convective type (ECT). ST was characterized by an obvious BB. ICT and ECT had almost the same 30-dBZ echo-top height of about $5.5 \mathrm{~km}$, and their strong echo region $(>40 \mathrm{dBZ})$ did not exceed the $0^{\circ} \mathrm{C}$ level $(4.4 \mathrm{~km}$ altitude $)$ even in their mature stages.

This paper describes and compares the characteristics of polarimetric radar variables in these three types of rainfalls in the Baiu front event over the East China Sea. The microphysical characteristics 


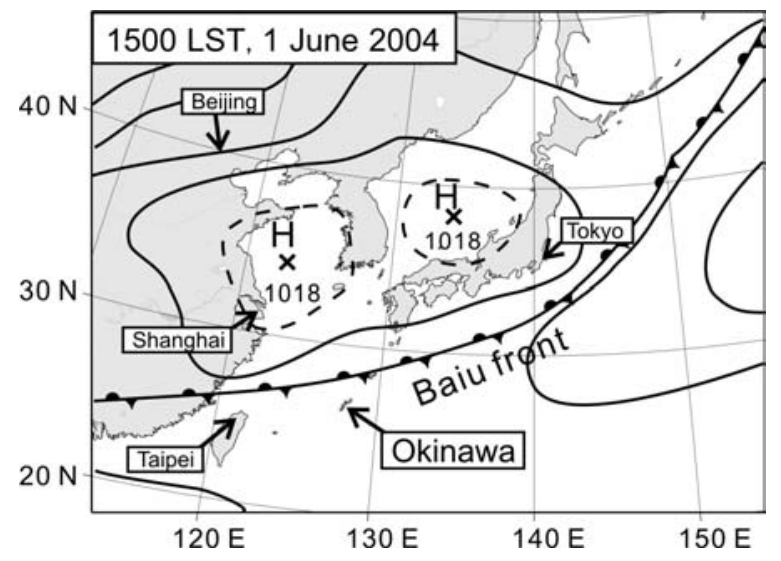

Fig. 1. Surface weather map at 1500 LST, 1 June 2004.

in these rainfall types are discussed on the basis of our observational results.

\section{Observation and rainfall types}

On 1 June 2004, the Baiu front, a significant subtropical frontal zone in East Asia, was located close to the Okinawa area as shown in Fig. 1. Figure 2 shows the locations of COBRA and the wind profiler facility at Ogimi. The temperature was $25.1^{\circ} \mathrm{C}$ at the surface, and the $0^{\circ} \mathrm{C}$ level was about $4.4 \mathrm{~km}$ at 1300 LST on 1 June from the rawin sonde data launched at the Ogimi wind profiler facility.

The horizontal distribution of radar reflectivity $\left(Z_{\mathrm{hh}}\right)$ at $2 \mathrm{~km}$ altitude at 1350 LST is shown in Fig. 2. Widespread stratiform rainfall was found in the northwestern part of the COBRA's observational area. Several isolated convective radar echoes were observed to the southeastern side of the stratiform rainfall area. Convective radar echoes with $Z_{\mathrm{hh}}$ larger than $40 \mathrm{dBZ}$ also appeared in the widespread stratiform rainfall area. In this study, we focus on these three representative types of rainfall appeared in Fig. 2. The areas A, B and C of $150 \mathrm{~km}^{2}$ in Fig. 2 are chosen for the following analysis.

The rainfall in area $\mathrm{A}$ is classified as stratiform category by the method of Steiner et al. (1995). An $\mathrm{BB}$ was obvious just below the $0^{\circ} \mathrm{C}$ level $(4.4 \mathrm{~km}$ altitude) as seen in the section a-a' in Fig. 3. We will refer to the rainfall in area $\mathrm{A}$ as "stratiform type (ST)". Areas B and C contained one convective rainfall system (convective cell) each, whose type of rainfall is judged by the method of Steiner et al. (1995). The convective rainfall in area B was iso-

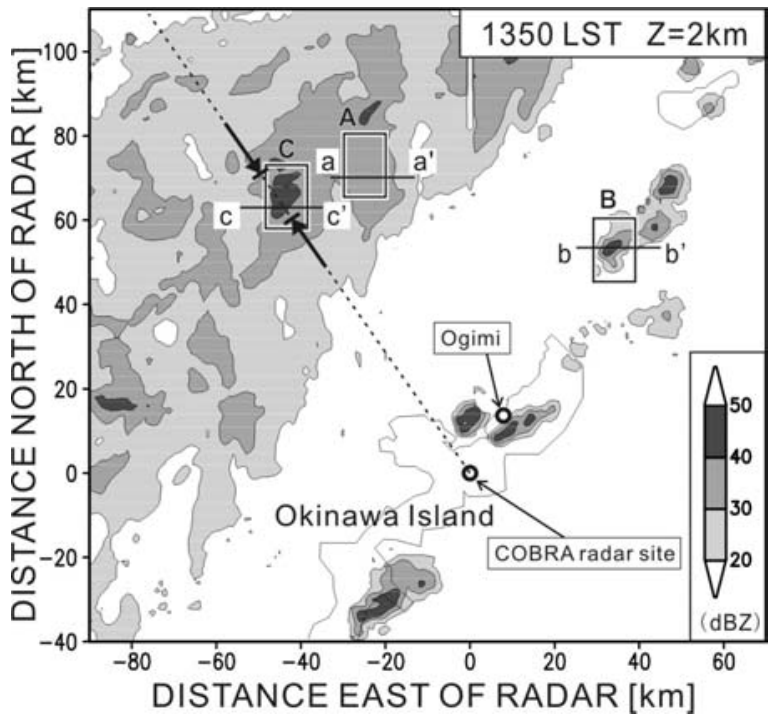

Fig. 2. Horizontal distribution of $Z_{\mathrm{hh}}$ at 1350 LST. The contours of $Z_{\mathrm{hh}}$ are drawn every $10 \mathrm{~dB}$ from $20 \mathrm{dBZ}$. Three rectangular areas A, B and C contain the rainfalls of stratiform type, isolated convective type and embedded convective type, respectively. The lines $a-a^{\prime}, b-b^{\prime}$ and $c-c^{\prime}$ denote the locations of the three vertical sections in Fig. 3. The arrows on the broken line indicate the position of Fig. 4.

lated, that is, stratiform rainfall was not observed around it. We will refer to the rainfall type in area B as "isolated convective type (ICT)". On the other hand, the convective rainfall in area $\mathrm{C}$ appeared and developed in the substantial stratiform rainfall area. We will refer to the rainfall type in area $\mathrm{C}$ as "embedded convective type (ECT)". To support the existence of a convective-scale circulation in ECT, distributions of Doppler velocity and $Z_{\mathrm{hh}}$ along the beam through ECT at an elevation of $0.9^{\circ}$ are shown in Fig. 4. An echo region stronger than $40 \mathrm{dBZ}$ is observed at a distance of about $75.5 \mathrm{~km}$ to $82 \mathrm{~km}$. Here, negative (positive) values of Doppler velocity indicate wind components away from (toward) the radar. Doppler velocity shows a local minimum value at a distance of $77 \mathrm{~km}$, and increases monotonically to a distance of $83.5 \mathrm{~km}$. Difference of Doppler velocity is about $6.5 \mathrm{~m} \mathrm{~s}^{-1}$ between these locations. These features indicate the presence of convective-scale convergence at low level in ECT. It seems reasonable to suppose that ECT is associated with a convective-scale updraft. 


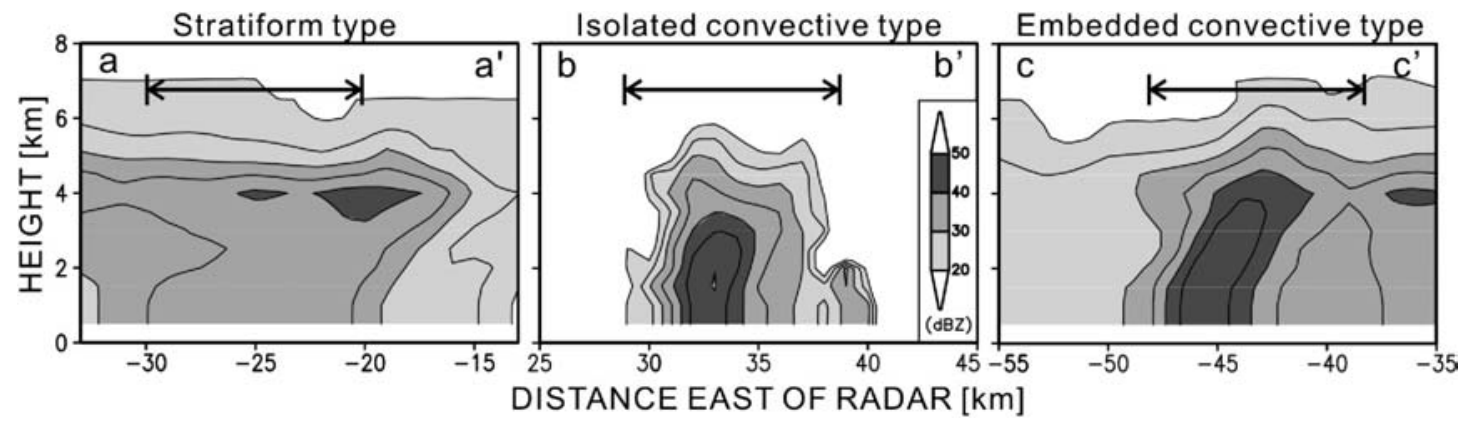

Fig. 3. Vertical distributions of $Z_{\mathrm{hh}}$ at $1350 \mathrm{LST}$. The contours of $Z_{\mathrm{hh}}$ are drawn every $5 \mathrm{~dB}$ from $20 \mathrm{dBZ}$. The locations of the sections are in Fig. 2. The arrows indicate the domains for the three rainfall types in the vertical sections.

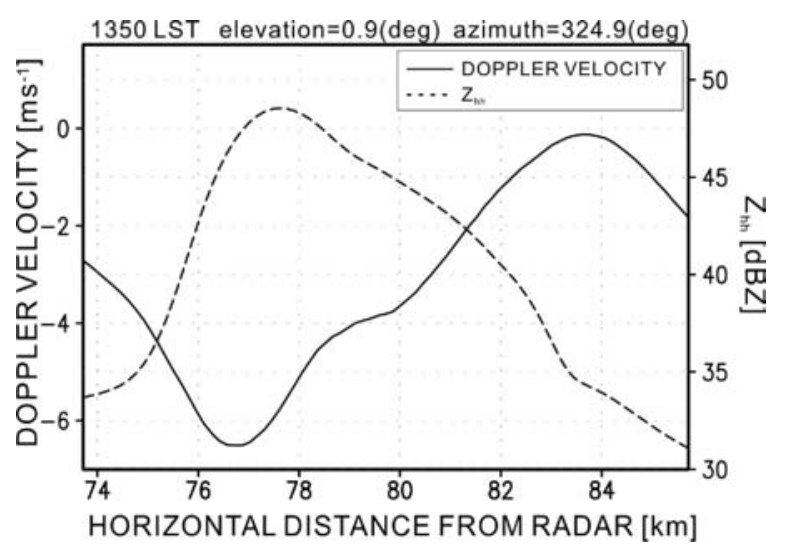

Fig. 4. Distributions of Doppler velocity (solid line) and $Z_{\mathrm{hh}}$ (broken line) along the beam through area $\mathrm{C}$ (embedded convective type) at an elevation of $0.9^{\circ}$. Here, negative (positive) values of Doppler velocity indicate wind components away from (toward) the radar. The position of the figure is indicated in Fig. 2.

Convective cells in areas $\mathrm{B}$ and $\mathrm{C}$ were in mature stages at 1350 LST. As seen from sections $b-b^{\prime}$ and c-c ${ }^{\prime}$ in Fig. 3, the convective rainfall in areas $\mathrm{B}$ and $\mathrm{C}$ had almost the same 30-dBZ echo-top height of about $5.5 \mathrm{~km}$. Their echo-top heights for the strong echo region $(>40 \mathrm{dBZ})$ did not exceed the $0^{\circ} \mathrm{C}$ level during their lifetimes (not shown). The next section describes the characteristics of polarimetric radar variables, $Z_{\mathrm{hh}}, Z_{\mathrm{dr}}$ and $\rho_{\mathrm{hv}}$, in the three rainfall types.

$Z_{\mathrm{dr}}$ is positive (negative) for particles with long axes near horizontally (vertically). For raindrops,
$Z_{\mathrm{dr}}$ is usually positive because raindrops tend to flatten while falling. The oblateness of raindrops increases with drop size, leading to the increase of $Z_{\mathrm{dr}}$ with drop size. $\rho_{\mathrm{hv}}$ depends on the dispersion in the ratio of the vertical-to-horizontal size of individual hydrometeors. For example, variation in drop-size distributions, drop oscillations, and irregular shapes of hydrometeors can be factors to reduce $\rho_{\mathrm{hv}} \cdot \rho_{\mathrm{hv}}$ is particularly sensitive to the presence of large wet particles such as melting aggregates.

PPI scan data were used in this study. COBRA was operated in a PPI scanning mode at the following elevation angles in less than 6 minutes: $0.5,0.9$, $1.4,2.0,2.6,3.4,4.3,5.5,6.8,8.5,10.5,13.0,16.1$ and $20.0^{\circ}$, although the time interval of this PPI scanning mode was 10 minutes. The transmitting polarization was +45 -degrees-tilt linear, and $\mathrm{H}$ and $\mathrm{V}$-independent digital receivers were used. The number of integration pulses was 32. The pulse width was $1 \mu \mathrm{s}$, and the resolution of the radar data was therefore $150 \mathrm{~m}$ in the radial direction. The rainfall attenuation in $Z_{\mathrm{hh}}$ and $Z_{\mathrm{dr}}$ was corrected by using the combined $\phi_{\mathrm{dp}}-Z_{\mathrm{dr}}$ constraint (Bringi and Chandrasekar 2001). The values of $\rho_{\mathrm{hv}}$ were corrected for signal-to-noise ratio (SNR) (see appendix). Low-SNR data of less than $15 \mathrm{~dB}$ were removed for the analysis of $Z_{\mathrm{dr}}$ and $\rho_{\mathrm{hv}}$.

\section{Characteristics of polarimetric variables}

\subsection{Vertical profiles of polarimetric variables}

Figures 5 and 6 show the scatter plots of $Z_{\mathrm{dr}}$ and $\rho_{\text {hv }}$ versus height within the areas A (ST), B (ICT) and $\mathrm{C}$ (ECT) in Fig. 2. The clustering feature of the plots in Figs. 5 and 6 is related to different elevation angles of PPI scans, which are described in Section 2. 

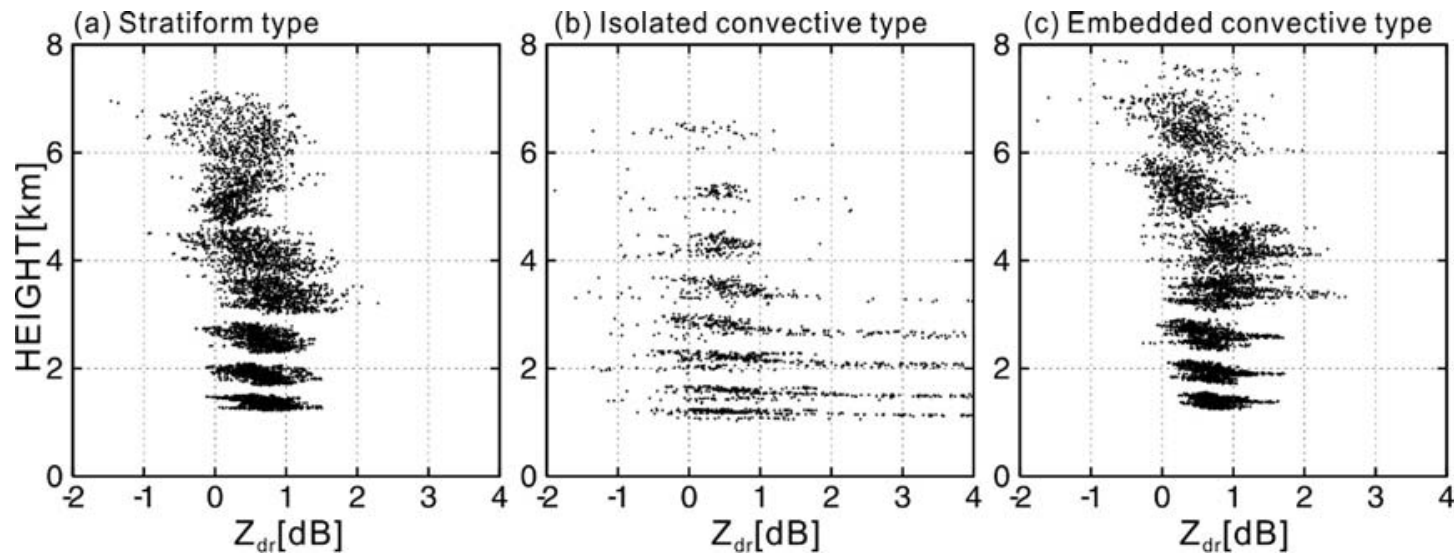

Fig. 5. Scatter plots of $Z_{\mathrm{dr}}$ versus height within areas (a) A (stratiform type), (b) B (isolated convective type) and (c) $\mathrm{C}$ (embedded convective type) in Fig. 2.
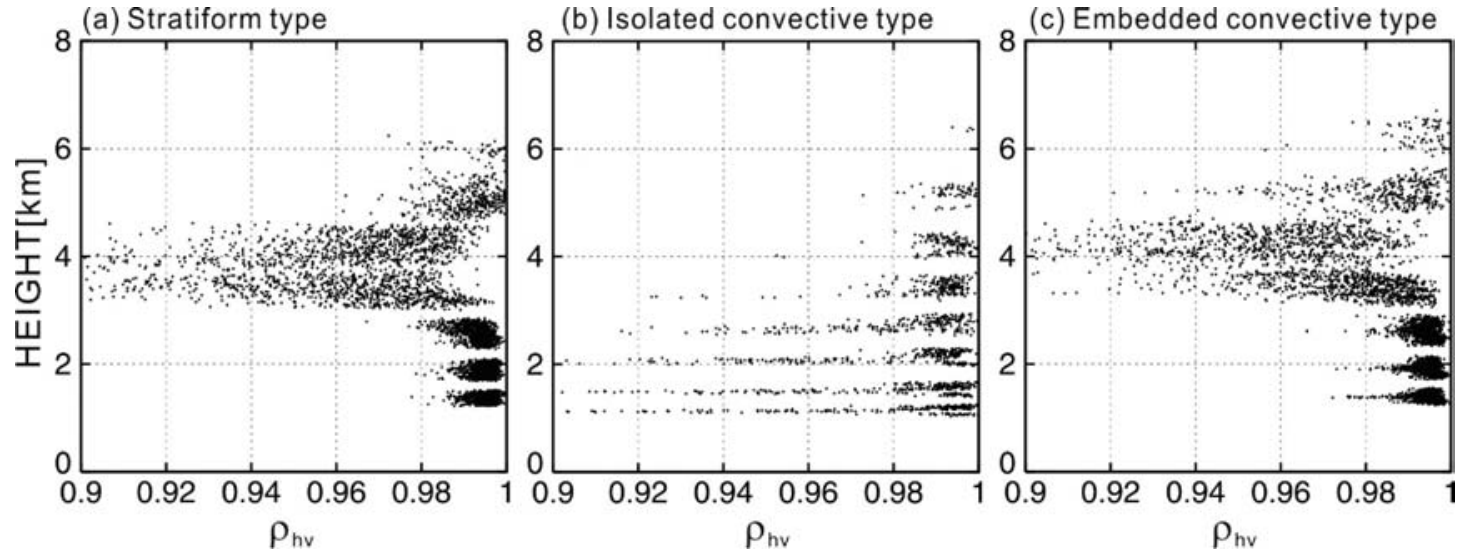

Fig. 6. As in Fig. 5, but for $\rho_{\mathrm{hv}}$.

In $\mathrm{ST}, Z_{\mathrm{dr}}$ ranges from 0 to $1.5 \mathrm{~dB}$ below $3 \mathrm{~km}$ altitude (Fig. 5a). Most of $\rho_{\text {hv }}$ are higher than 0.98 at these levels (Fig. 6a). Between $3 \mathrm{~km}$ and $4.5 \mathrm{~km}$ altitudes (near the $0^{\circ} \mathrm{C}$ level), where a $\mathrm{BB}$ of $40 \mathrm{dBZ}$ to $45 \mathrm{dBZ}$ is obvious in section a-a' in Fig. $3, Z_{\mathrm{dr}}$ values are slightly larger than those at lower levels, and reach up to $2 \mathrm{~dB}$ (Fig. 5a). As seen in Fig. 6a, $\rho_{\text {hv }}$ values generally decrease and are widely scattered around the $\mathrm{BB}$, and $\rho_{\mathrm{hv}}$ higher than 0.99 is scarce. These features indicate the presence of a layer consisting of different kinds of particles including melting heavily aggregated snow just below the $0^{\circ} \mathrm{C}$ level because $\rho_{\mathrm{hv}}$ is sensitive to the presence of large wet particles as has been described in several previous studies (e.g., Brandes and Ikeda 2004). Above $4.5 \mathrm{~km}$ altitude, where snow particles should be dominant, $Z_{\mathrm{dr}}$ ranges from $-0.5 \mathrm{~dB}$ to $1.5 \mathrm{~dB}$ (Fig. $5 \mathrm{a}$ ), and most of $\rho_{\mathrm{hv}}$ are higher than 0.98 (Fig. 6a).

A prominent feature in ICT is the wide variations in $Z_{\mathrm{dr}}$ and $\rho_{\mathrm{hv}}$ at lower levels (Figs. 5b, 6b). The values of $Z_{\mathrm{dr}}$ distribute up to around $4 \mathrm{~dB}$ in ICT at lower levels, while those in ST and ECT distribute up to $1.5 \mathrm{~dB}$ at most (Fig. 5). Around the $0^{\circ} \mathrm{C}$ level, no $\mathrm{BB}$ is observed in ICT (section $\mathrm{b}-\mathrm{b}^{\prime}$ in Fig. 3), and most of $\rho_{\mathrm{hv}}$ are higher than 0.98 (Fig. 6b). These facts indicate that a melting layer is not obvious in ICT.

In ECT, $Z_{\mathrm{dr}}$ values range from $0 \mathrm{~dB}$ to $1.5 \mathrm{~dB}$, and most of $\rho_{\mathrm{hv}}$ are higher than 0.98 at lower levels (Figs. 5c, 6c). Note that these distributions of the values are almost the same as those in ST (Figs. 5a, 6a), although the maximum value and distribution pattern of $Z_{\mathrm{hh}}$ in ECT are largely different 


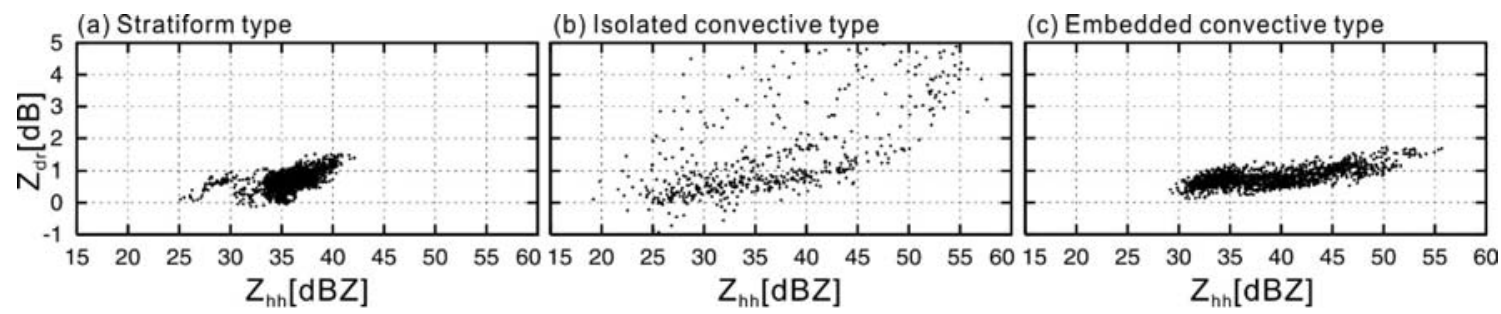

Fig. 7. $Z_{\mathrm{dr}}$ versus $Z_{\mathrm{hh}}$ below $2 \mathrm{~km}$ altitude within areas (a) A (stratiform type), (b) B (isolated convective type) and (c) C (embedded convective type) in Fig. 2.

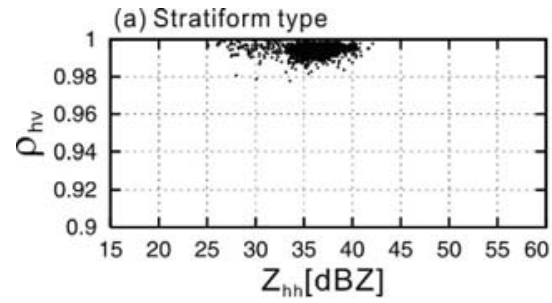

(b) Isolated convective type

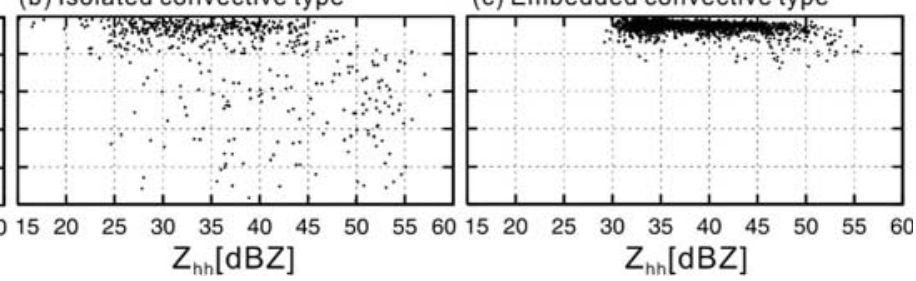

Fig. 8. As in Fig. 7, but for $\rho_{\mathrm{hv}}$ versus $Z_{\mathrm{hh}}$.

from those in ST. A BB is not obvious as seen in section c-c' in Fig. 3. However, $\rho_{\text {hv }}$ values decrease and are widely scattered around the $0^{\circ} \mathrm{C}$ level as plotted in Fig. 6c. The scattering feature of $\rho_{\mathrm{hv}}$ is observed in all ranges of $Z_{\mathrm{hh}}$ around the $0^{\circ} \mathrm{C}$ level (not shown). This indicates the existence of mixedphase hydrometeors around and just below the $0^{\circ} \mathrm{C}$ level not only in the surrounding stratiform parts but in the convective part of ECT.

The above-mentioned characteristics of the scatter plots of $Z_{\mathrm{dr}}$ and $\rho_{\mathrm{hv}}$ versus height in ICT and ECT did not show significant changes during their mature stage (at least at 1340 LST, 1350 LST and 1400 LST). It is safe to say that the characteristics of the vertical profiles of $Z_{\mathrm{dr}}$ and $\rho_{\mathrm{hv}}$ in ECT are generally similar to those in ST rather than those in ICT throughout the precipitation depth, although the vertical profiles of $Z_{\mathrm{hh}}$ in ICT and ECT are almost equal. A detailed comparison of polarimetric variables for raindrops near the surface for the three types of rainfalls will be presented in the following section.

\subsection{Polarimetric variables near the surface}

$Z_{\mathrm{dr}}$ and $\rho_{\mathrm{hv}}$ below $2 \mathrm{~km}$ altitude are plotted against $Z_{\text {hh }}$ in Figs. 7, 8, respectively, to characterize the three rainfall types near the surface that were sufficiently below the $0^{\circ} \mathrm{C}$ level in which com- plete melting is assured. In ST, $Z_{\mathrm{hh}}$ is observed up to approximately $40 \mathrm{dBZ}$ (Figs. 7a, 8a). $Z_{\mathrm{dr}}$ increases with $Z_{\mathrm{hh}}$ in the region with $Z_{\mathrm{hh}}$ stronger than $35 \mathrm{dBZ}$ (Fig. 7a). Most $\rho_{\mathrm{hv}}$ is higher than 0.98 in all ranges of $Z_{\mathrm{hh}}$ (Fig. 8a).

In ICT, $Z_{\mathrm{dr}}$ slightly increases with $Z_{\mathrm{hh}}$ and most $\rho_{\mathrm{hv}}$ is higher than 0.98 in the region with $Z_{\mathrm{hh}}$ weaker than $45 \mathrm{dBZ}$ (Figs. 7b, 8b). On the other hand, $Z_{\mathrm{dr}}$ suddenly increases and $\rho_{\mathrm{hv}}$ drastically decreases with $Z_{\mathrm{hh}}$ in the region with $Z_{\mathrm{hh}}$ stronger than $45 \mathrm{dBZ}$ (Figs. 7b, 8b). These relations indicate the existence of large raindrops in the reflectivity core in ICT.

The values of $Z_{\mathrm{dr}}$ and $\rho_{\mathrm{hv}}$ in ICT are more scattered at each $Z_{\mathrm{hh}}$ than in the other two types. However the increase in $Z_{\mathrm{dr}}$ and the decrease in $\rho_{\mathrm{hv}}$ in the reflectivity cores of isolated convective rainfalls are significant features in spatial distribution as seen in Fig. 9 (relation of $Z_{\mathrm{dr}}$ to $Z_{\mathrm{hh}}$ not shown). $\rho_{\text {hv }}$ values clearly decrease in the reflectivity cores of all four convective cells depicted in Fig. 9. Some negative $Z_{\mathrm{dr}}$ values are also found in ICT (Fig. 7b). They should be attributed measurement fluctuations or some kind of noise, although they are hardly observed in ST and ECT.

In ECT, the maximum $Z_{\mathrm{hh}}$ is approximately $55 \mathrm{dBZ}$ (Figs. 7c, 8c), which is a comparable value to that in ICT. However, $Z_{\mathrm{dr}}$ exhibited only a grad- 


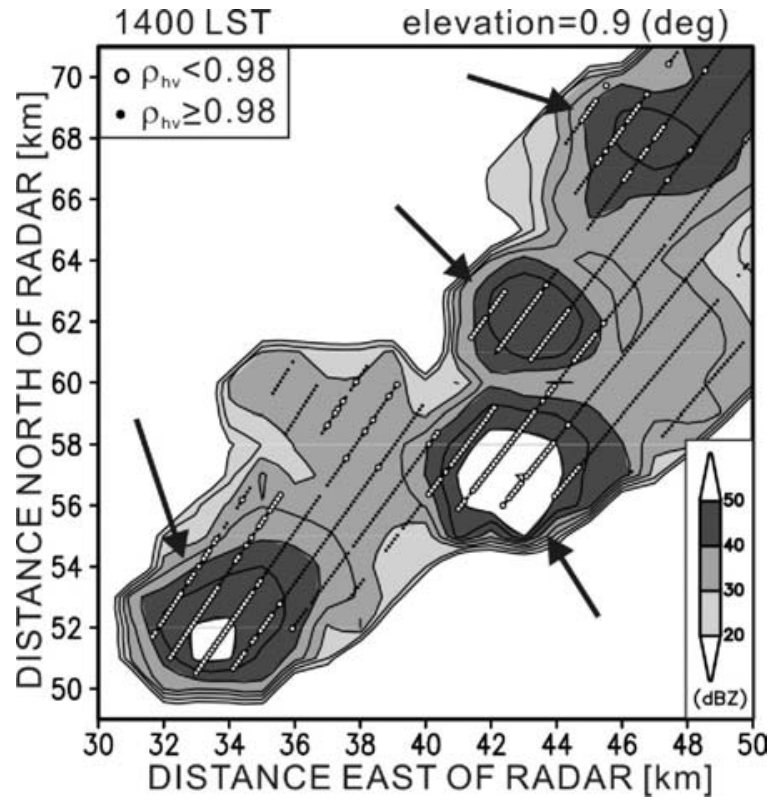

Fig. 9. The example of PPI display at an elevation of $0.9^{\circ}$ for $Z_{\mathrm{hh}}$ and $\rho_{\mathrm{hv}}$ for isolated convective rainfalls, which are indicated by arrows. The contours of $Z_{\mathrm{hh}}$ are drawn every $5 \mathrm{~dB}$ from $20 \mathrm{dBZ}$. The open circles indicate $\rho_{\text {hv }}$ of less than 0.98 and the closed circles of not less than this.

ual increase with $Z_{\mathrm{hh}}$ in all ranges of $Z_{\mathrm{hh}}$ (Fig. 7c). Note that $Z_{\mathrm{dr}}$ values in ECT are generally smaller than those in ICT in the intense rainfall regions with $Z_{\mathrm{hh}}$ stronger than $45 \mathrm{dBZ}$ (Figs. 7b, 7c). This indicates that smaller raindrops are more dominant in ECT than in ICT at the same $Z_{\mathrm{hh}}$ in the intense rainfall regions. Most $\rho_{\text {hv }}$ is higher than 0.98 in ECT, and do not show a significant descent even in the region with $Z_{\mathrm{hh}}$ stronger than $45 \mathrm{dBZ}$ (Fig. $8 \mathrm{c})$.

To show that the different character in dominant raindrop sizes between ICT and ECT is not attributed to the difference in life stages of convective cells, the values of averaged $Z_{\mathrm{dr}}$ were calculated for each $5-\mathrm{dB}$ increment in $Z_{\mathrm{hh}}$ using the data below $2 \mathrm{~km}$ altitude at 1340, 1350 and 1400 LST (Fig. 10). The convective cell in ICT was observed first at 1330 LST and last at 1410 LST, and was completely traced using the data of 10-minute intervals during its lifetime. Its maximum $Z_{\mathrm{hh}}$ reaches 55-dBZ category at 1340, 1350 and 1400 LST at low levels. We can consider that the convective cell

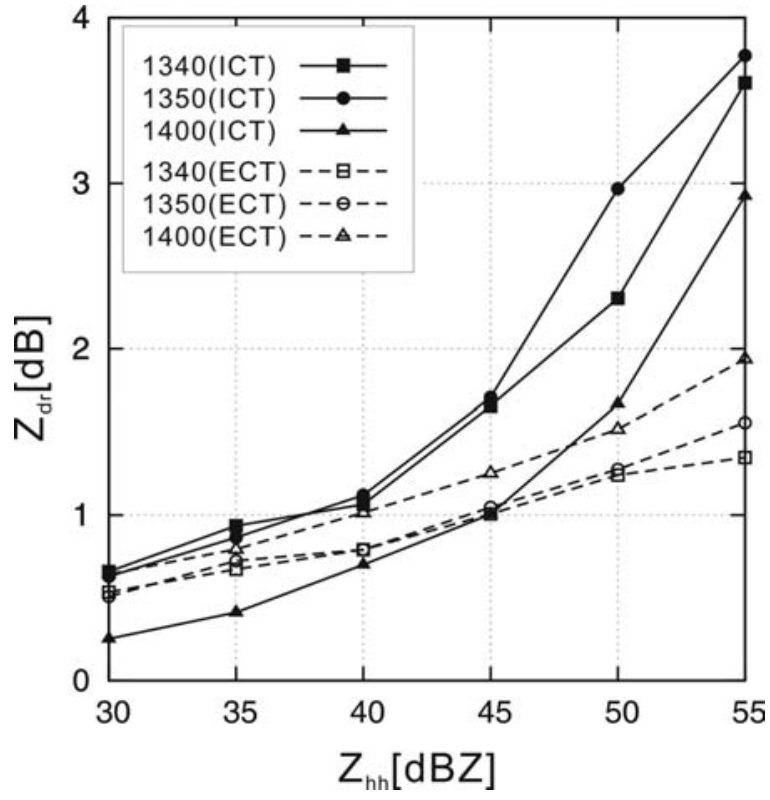

Fig. 10. Averaged $Z_{\mathrm{dr}}$ for each 5-dB increment in $Z_{\mathrm{hh}}$ versus $Z_{\mathrm{hh}}$. Data for the ICT and ECT at 1340, 1350 and 1400 LST.

in ICT is at the mature stage at around 1350 LST. As seen in Fig. 10, the averaged $Z_{\mathrm{dr}}$ in ICT remarkably increases in the region with $Z_{\mathrm{hh}}$ larger than $45 \mathrm{dBZ}$, and ranges from $2.9 \mathrm{~dB}$ to $3.8 \mathrm{~dB}$ for $55 \mathrm{dBZ}$ in $Z_{\mathrm{hh}}$ from 1340 to $1400 \mathrm{LST}$. The convective cell in ECT is also at the intense stage with maximum $Z_{\mathrm{hh}}$ of $55-\mathrm{dBZ}$ category at 1340,1350 and 1400 LST. The averaged $Z_{\mathrm{dr}}$ in ECT shows only a gradual increase even in the region with $Z_{\mathrm{hh}}$ larger than $45 \mathrm{dBZ}$ and ranges from $1.3 \mathrm{~dB}$ to $1.9 \mathrm{~dB}$ for $55 \mathrm{dBZ}$ in $Z_{\mathrm{hh}}$ from 1340 to $1400 \mathrm{LST}$. It is reasonable to say that the larger $Z_{\mathrm{dr}}$ in ICT and smaller $Z_{\mathrm{dr}}$ in ECT in the intense rainfall regions are not temporary and are not attributed to the life stages of convective cells. In addition, 13 isolated convective rainfalls and 12 embedded convective rainfalls with their maximum $Z_{\mathrm{hh}}$ of at least 55-dBZ category below $2 \mathrm{~km}$ altitude were observed by COBRA in 12 volume-scan data from 1300 to 1450 LST over the ocean area. Averaged $Z_{\mathrm{dr}}$ at $55 \mathrm{dBZ}$ is $3.1 \mathrm{~dB}$ for all those isolated convective rainfalls and $1.9 \mathrm{~dB}$ for embedded convective rainfalls. This result also supports that the feature of larger raindrops in ICT and smaller raindrops in ECT in their intense rainfall regions is common in this Baiu rainfall event. 


\section{Discussion}

\subsection{Vertical profiles of polarimetric variables and melting layer signatures}

The characteristics of the vertical profiles of $Z_{\mathrm{dr}}$ and $\rho_{\mathrm{hv}}$ in ECT are more similar to those in ST rather than to those in ICT throughout the precipitation depth, although the vertical profiles of $Z_{\mathrm{hh}}$ in ICT and ECT are almost equal. One noteworthy feature in ST and ECT is the overall increase in $Z_{\mathrm{dr}}$ and decrease in $\rho_{\mathrm{hv}}$ around the $0^{\circ} \mathrm{C}$ level (Figs. $5,6)$. These polarimetric signatures indicate the existence of melting layers in ST and ECT as described in previous studies (Ryzhkov and Zrnić 1998; Brandes and Ikeda 2004; Ikeda et al. 2005). In ST, the melting layer signature also manifests as a BB in $Z_{\mathrm{hh}}$ field. In ECT, however, a BB is not obvious, and a decrease of $Z_{\text {hh }}$ just under the polarimetric melting layer which is exhibited by $Z_{\mathrm{dr}}$ and $\rho_{\text {hv }}$ is not observed (Fig. 3c).

The range of $Z_{\mathrm{dr}}$ values under the polarimetric melting layer in ECT is comparable to that in ST as shown in Figs. $5 \mathrm{a}$ and $5 \mathrm{c}$. This fact indicates that the larger $Z_{\mathrm{hh}}$ values below the polarimetric melting layer in ECT than in ST is not attributed to the difference in dominant raindrop size so much. It is more likely that the number concentration of raindrops below the melting layer in ECT is higher than that in ST. In stratiform rainfalls, the precipitation fall velocity generally increases at the bottom of the BB as the low density snow particles melt to form raindrops (Fabry et al. 1994), which is one of the important factors to reduce the number concentration of raindrops, and hence to reduce the values of $Z_{\mathrm{hh}}$ at the region. In ECT, a convective updraft would sustain raindrops around the bottom of the melting layer and prevent the rapid decrease in number concentration of raindrops in the region. In addition, precipitation formation below the melting level, which is significant for convective systems during the Baiu season (Zhang et al. 2006), may contribute to increase $Z_{\mathrm{hh}}$ under the polarimetric melting layer in ECT. High temporal resolution data of vertical air velocity and precipitation fall velocity, as well as the polarimetric radar variables, will help to discuss further details about the absence of a BB in ECT.

\subsection{Raindrop sizes near the surface}

Near the surface sufficiently below the $0^{\circ} \mathrm{C}$ level, ICT had larger $Z_{\mathrm{dr}}$ than ECT in the region with $Z_{\mathrm{hh}}$ stronger than $45 \mathrm{dBZ}$. This indicates that larger raindrops were more dominant in ICT than in ECT at the same $Z_{\mathrm{hh}}$ in intense rainfall regions. Extremely low values of $\rho_{\mathrm{hv}}$ in the region with $Z_{\mathrm{hh}}$ stronger than $45 \mathrm{dBZ}$ in ICT are consistent with the presence of large raindrops (e.g. Ryzhkov and Zrnić 2005). Bringi et al. (2006) provided the bestfit lines between $Z_{\mathrm{dr}}$ (as a ratio and not in $\mathrm{dB}$ in the following expressions) and the median volume diameter $\left(D_{0}\right)$ for a Baiu front event in Okinawa from $2 \mathrm{D}$-video disdrometer data and a simulation of $Z_{\mathrm{dr}}$ at a frequency of $5.4 \mathrm{GHz}$ :

$$
\begin{array}{ll}
D_{0}=3.984 Z_{\mathrm{dr}}^{\text {ratio }}-3.2303 ; \mathrm{mm} & \left(Z_{\mathrm{dr}}^{\text {ratio }}<1.3\right) \\
D_{0}=0.733 Z_{\mathrm{dr}}^{\text {ratio }}-0.9088 ; \mathrm{mm} & \left(Z_{\mathrm{dr}}^{\text {ratio }}>1.3\right)
\end{array}
$$

During the mature period of ICT and ECT, depicted in Fig. 10, the averaged $Z_{\mathrm{dr}}$ for $55 \mathrm{dBZ}$ in $Z_{\mathrm{hh}}$ ranges from $2.9 \mathrm{~dB}$ to $3.8 \mathrm{~dB}$ in ICT and from $1.3 \mathrm{~dB}$ to $1.9 \mathrm{~dB}$ in ECT. Using the above relationships, $D_{0}$ is retrieved and ranges from $2.3 \mathrm{~mm}$ to $2.7 \mathrm{~mm}$ in ICT and from $1.9 \mathrm{~mm}$ to $2.0 \mathrm{~mm}$ in ECT for $55 \mathrm{dBZ}$ in $Z_{\mathrm{hh}}$.

Several earlier studies showed the time evolution of the averaged $Z_{\mathrm{dr}}$ versus $Z_{\mathrm{hh}}$ from the early growth phase to the mature phase of convective cells (e.g., Caylor and Illingworth 1987; Illingworth 1988; Bringi et al. 1991). In their studies, the initial stages of the cloud were characterized by low $Z_{\mathrm{hh}}$ and unusually large $Z_{\mathrm{dr}}$ implying a very low number concentration of large raindrops developed through a warm rain process. As time increased, $Z_{\mathrm{dr}}$ for a given $Z_{\mathrm{hh}}$ tended to decrease to the relationship of Marshall-Palmer DSD. They concluded that this evolution is consistent with weakening updrafts and the beginning of downdrafts in the cell, and the mixed-phase and ice-phase processes became important as the cloud grew above the $0^{\circ} \mathrm{C}$ level. In the present study, however, the raindropsize difference between ICT and ECT is presented as the character for their mature stages, and do not result from the difference of cell-stages as described in Fig. 10.

In ICT, the echo-top height for the strong echo region of $40 \mathrm{dBZ}$ did not exceed the $0^{\circ} \mathrm{C}$ level during the lifetime of the convective cell. In addition, the melting layer signature of low $\rho_{\mathrm{hv}}$ was not obvious in ICT. These facts suggest that the large raindrops in ICT were formed mainly by a warm-rain process that is accompanied by the efficient diffusional growth of cloud droplets and the coalescence growth of raindrops.

Smaller raindrops in ECT than in ICT obviously reflect the difference in rain-formation processes be- 
tween ECT and ICT. As discussed in Section 4.1, one of the noteworthy features in ECT is the existence of the polarimetric melting layer. This implies that the mixed-phase and ice-phase processes also contributed to the rain production in ECT. However, in this study, it is difficult to discuss the role of the mixed-phase and ice-phase hydrometeors at upper levels to the formation of smaller raindrops near the surface in ECT. To understand the detailed rain-formation processes, in-situ observations of cloud microphysical and dynamical features, such as size distributions of cloud particles and raindrops, relative humidity, and updraft velocity in the rainfall systems, should be required in the future in addition to the polarimetric radar observation with higher temporal resolution. Also, numerical modeling studies with detailed cloud microphysics including the processes of colliding and breaking up of raindrops would be helpful for further discussion of the different precipitation-growth processes between ICT and ECT.

\section{Summary}

This study described and compared the characteristics of polarimetric radar variables in three types of rainfalls in a Baiu front event over the East China Sea using the C-band polarimetric radar (COBRA). The selected rainfall cases were common types in the Baiu season: (1) stratiform type (ST), (2) isolated convective type (ICT) and (3) embedded convective type (ECT). ST was accompanied by an obvious bright band (BB). ICT and ECT had convective cells of the 40-dBZ echotop heights which did not exceed the $0^{\circ} \mathrm{C}$ level (4.4 $\mathrm{km}$ altitude) even in their mature stages. Maximum values of $Z_{\mathrm{hh}}$ (about $55 \mathrm{dBZ}$ ) and $30-\mathrm{dBZ}$ echo-top heights were almost equal in ICT and ECT. However, the characteristics of the vertical profiles of $Z_{\mathrm{dr}}$ and $\rho_{\mathrm{hv}}$ in ECT were more similar to those in ST rather than to those in ICT.

One noteworthy feature in ECT and ST is the overall decrease in $\rho_{\mathrm{hv}}$ and increase in $Z_{\mathrm{dr}}$ around the $0^{\circ} \mathrm{C}$ level. This indicates the existence of melting layers in ECT and ST, although a BB was not obvious in ECT. It follows from this that previous methods of convective-stratiform classification using radar reflectivity fields (e.g., Churchill and Houze 1984; Steiner et al. 1995; Rosenfeld et al. 1995) do not always effectively characterize the properties of hydrometeors around the $0^{\circ} \mathrm{C}$ level in precipitation systems during the Baiu season over the East China Sea. Developing a method of rainfall-type classification judging the presence of a melting layer using polarimetric radar variables in addition to the traditional classification of convective-stratiform regions could be useful for upgrading rain-retrieval algorithms for radars and microwave radiometers on satellites (e.g., TRMM and GPM).

Near the surface sufficiently below the $0^{\circ} \mathrm{C}$ level, ICT had larger $Z_{\mathrm{dr}}$ than ECT in the region with $Z_{\mathrm{hh}}$ stronger than $45 \mathrm{dBZ}$. This indicates that larger raindrops were more dominant in ICT than in ECT at the same $Z_{\mathrm{hh}}$ in intense rainfall regions. Extremely low values of $\rho_{\mathrm{hv}}$ in the region with $Z_{\mathrm{hh}}$ stronger than $45 \mathrm{dBZ}$ in ICT are consistent with the presence of large raindrops. This difference of dominant raindrop sizes appears to reflect the difference in precipitation growth processes between ICT and ECT, although their echo-top heights of $30 \mathrm{dBZ}$ and maximum $Z_{\mathrm{hh}}$ near the surface were almost equal.

In ICT, the echo-top height for the strong echo region of $40 \mathrm{dBZ}$ did not exceed the $0^{\circ} \mathrm{C}$ level during the lifetime of the convective cell. In addition, the melting layer signature of low $\rho_{\mathrm{hv}}$ and large $Z_{\mathrm{dr}}$ was not obvious in ICT. These facts suggest that the large raindrops in ICT were formed mainly by a warm-rain process. In ECT, the existence of a melting layer implies that the mixed-phase and icephase processes also contributed to the rain production in ECT. However, the detailed microphysical processes in the smaller raindrop formation in ECT than in ICT still remain as future issues. Intensive in-situ observations of microphysical and dynamical features of the rainfall systems and numerical modeling studies with detailed cloud microphysics can be helpful for further investigations of the precipitation growth processes in each type of rainfall systems.

\section{Acknowledgements}

We wish to thank Dr. Koyuru Iwanami of National Research Institute for Earth Science and Disaster Prevention (NIED) for the productive discussions and for his suggestions. We would also like to thank Mr. Hiroshi Hanado, Mr. Shinya Sekizawa and Dr. Yasushi Kitamura of NICT, for their useful comments. Our heartfelt thanks are also extended to all of the researchers and staff members of Okinawa Subtropical Environment RemoteSensing Center, NICT, for their continuous support and encouragement. This study was conducted as part of the Global Satellite Mapping of Precipita- 
tion (GSMaP) project supported by the Core Research for Evolutional Science and Technology (CREST) program of Japan Science and Technology.

\section{Appendix}

\section{Correction of $\rho_{\mathrm{hv}}$ for the signal-to-noise ratio}

The correlation coefficient between horizontal and vertical polarization signals $\left(\rho_{\text {hv }}\right)$ is defined as,

$$
\rho_{\mathrm{hv}}=\frac{\left|\left\langle s_{\mathrm{vv}} s_{\mathrm{hh}}^{*}\right\rangle\right|}{\sqrt{\left\langle\left|s_{\mathrm{hh}}\right|^{2}\right\rangle} \sqrt{\left\langle\left|s_{\mathrm{vv}}\right|^{2}\right\rangle}},
$$

where $s_{\mathrm{hh}}$ and $s_{\mathrm{Vv}}$ are scattering coefficients at horizontal and vertical polarization signals and the angle brackets denote the ensemble average. $\rho_{\mathrm{hv}}$ in the presence of noise can be expressed as,

$$
\tilde{\rho}_{\mathrm{hv}}=\frac{\left|\left\langle\left(s_{\mathrm{vv}}+n_{\mathrm{vv}}\right)\left(s_{\mathrm{hh}}^{*}+n_{\mathrm{hh}}^{*}\right)\right\rangle\right|}{\sqrt{\left\langle\left|s_{\mathrm{hh}}+n_{\mathrm{hh}}\right|^{2}\right\rangle} \sqrt{\left\langle\left|s_{\mathrm{vv}}+n_{\mathrm{vv}}\right|^{2}\right\rangle}},
$$

where $\tilde{\rho}_{\text {hv }}$ is the correlation coefficient between horizontal and vertical polarization signals in the presence of noise and $n_{\mathrm{hh}}$ and $n_{\mathrm{vv}}$ are noise signals at horizontal and vertical polarizations. With the assumption of $\left\langle s_{\mathrm{hh}} n_{\mathrm{hh}}^{*}\right\rangle=\left\langle n_{\mathrm{hh}} s_{\mathrm{hh}}^{*}\right\rangle=\left\langle s_{\mathrm{vv}} n_{\mathrm{vv}}^{*}\right\rangle=$ $\left\langle n_{\mathrm{vv}} s_{\mathrm{vv}}^{*}\right\rangle=\left\langle s_{\mathrm{vv}} n_{\mathrm{hh}}^{*}\right\rangle=\left\langle n_{\mathrm{vv}} s_{\mathrm{hh}}^{*}\right\rangle=\left\langle n_{\mathrm{vv}} n_{\mathrm{hh}}^{*}\right\rangle=0$, (A2) can be expanded as,

$$
\begin{aligned}
& \tilde{\rho}_{\mathrm{hv}}=\frac{\left|\left\langle s_{\mathrm{Vv}} s_{\mathrm{hh}}^{*}\right\rangle\right|}{\sqrt{\left\langle\left|S_{\mathrm{hh}}\right|^{2}\right\rangle+\left\langle\left|n_{\mathrm{hh}}\right|^{2}\right\rangle} \sqrt{\left\langle\left|s_{\mathrm{vv}}\right|^{2}\right\rangle+\left\langle\left|n_{\mathrm{vv}}\right|^{2}\right\rangle}} \\
& =\frac{\left|\left\langle s_{\mathrm{vv}} s_{\mathrm{hh}}^{*}\right\rangle\right|}{\sqrt{\left\langle\left|s_{\mathrm{hh}}\right|^{2}\right\rangle} \sqrt{\left\langle\left|s_{\mathrm{vv}}\right|^{2}\right\rangle}} \\
& \times \frac{\left.\sqrt{\left\langle\left|s_{\mathrm{hh}}\right|^{2}\right.}\right\rangle \sqrt{\left\langle\left|s_{\mathrm{vv}}\right|^{2}\right\rangle}}{\sqrt{\left\langle\left|s_{\mathrm{hh}}\right|^{2}\right\rangle+\left\langle\left|n_{\mathrm{hh}}\right|^{2}\right\rangle} \sqrt{\left\langle\left|s_{\mathrm{vv}}\right|^{2}\right\rangle+\left\langle\left|n_{\mathrm{vv}}\right|^{2}\right\rangle}}
\end{aligned}
$$

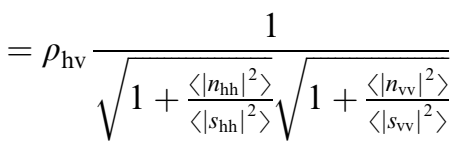

$$
\begin{aligned}
& =\rho_{\mathrm{hv}} \frac{1}{\sqrt{1+\frac{1}{\mathrm{SNR}_{\mathrm{h}}}} \sqrt{1+\frac{1}{\mathrm{SNR}_{\mathrm{v}}}}},
\end{aligned}
$$

where $\mathrm{SNR}_{\mathrm{h}}$ and $\mathrm{SNR}_{\mathrm{v}}$ are signal-to-noise ratios in the horizontal and vertical channels, respectively, and are given by $\mathrm{SNR}_{\mathrm{h}}=\frac{\left\langle\left|s_{\mathrm{hh}}\right|^{2}\right\rangle}{\left\langle\left|n_{\mathrm{hh}}\right|^{2}\right\rangle}$ and $\mathrm{SNR}_{\mathrm{v}}=$ $\frac{\left\langle\left|s_{\mathrm{vv}}\right|^{2}\right\rangle}{\left\langle\left|n_{\mathrm{vv}}\right|^{2}\right\rangle}$. With the assumption of $\mathrm{SNR}=\mathrm{SNR}_{\mathrm{h}}=$ $\mathrm{SNR}_{\mathrm{v}}$, we can express (A3) as,

$$
\begin{aligned}
\rho_{\mathrm{hv}} & =\tilde{\rho}_{\mathrm{hv}}\left(1+\frac{1}{\mathrm{SNR}}\right) \\
& =\tilde{\rho}_{\mathrm{hv}}\left(1+10^{-\mathrm{SNRdB} / 10}\right),
\end{aligned}
$$

where SNRdB is the signal-to-noise ratio in units of dB. Observation data are corresponding to $\tilde{\rho}_{\mathrm{hv}}$ in (A4). Using the relationship of (A4), expected value of $\rho_{\mathrm{hv}}$ corrected for the signal-to-noise ratio can be deduced from $\tilde{\rho}_{\mathrm{hv}}$.

\section{References}

Brandes, E. A., and K. Ikeda, 2004: Freezing-level estimation with polarimetric radar, J. Appl. Meteor., 43, 1541-1553.

Bringi, V. N., D. A. Burrows, and S. M. Menon, 1991: Multiparameter radar and aircraft study of raindrop spectral evolution in warm-based clouds. $J$. Appl. Meteor., 30, 853-880.

Bringi, V. N., M. Thurai, K. Nakagawa, G. J. Huang, T. Kobayashi, A. Adachi, H. Hanado, and S. Sekizawa, 2006: Rainfall estimation from C-band polarimetric radar in Okinawa, Japan: Comparisons with 2D-video disdrometer and $400 \mathrm{MHz}$ wind profiler. J. Meteor. Soc. Japan, 84, No. 4, 705724.

Bringi, V. N., and V. Chandrasekar, 2001: Polarimetric Doppler weather radar: Principles and applications. Cambridge University Press, 636 pp.

Caylor, I. J., and A. J. Illingworth, 1987: Radar observations and modeling of warm rain initiation. Quart. J. Roy. Meteor. Soc., 113, 1171-1191.

Chen, J., H. Uyeda, and D. -I. Lee, 2003: A method using radar reflectivity data for the objective classification of precipitation during the Baiu season. $J$. Meteor. Soc. Japan, 81, 229-249.

Churchill, D. D., and R. A. Houze Jr., 1984: Development and structure of winter monsoon cloud clusters on 10 December 1978. J. Atmos. Sci., 41, 933-960.

Fabry, F., Bellon, A., and Zawadzki, 1994: Long term observations of the melting layer using vertically pointing radars. Rechnical Report of Cooperative Center for Research in Mesometeorology (CCRM), MW-101, 64 pp.

Iguchi, T., T. Kozu, R. Meneghini, J. Awaka, and K. Okamoto, 2000: Rain-profiling algorithm for the TRMM precipitation radar. J. Appl. Meteor., 39, 2038-2052.

Ikeda, K., E. A. Brandes, and R. M. Rasmussen, 2005: Polarimetric radar observations of multiple freezing levels. J. Atmos. Sci., 62, 3624-3636.

Illingworth, A. J., 1998: The formation of rain in convective clouds. Nature., 336, 754-756.

Nakagawa, K., H. Hanado, S. Satoh, N. Takahashi, T. Iguchi, and K. Fukutani, 2003: Development of 
a new C-band bistatic polarimetric radar and observation of typhoon events. Proc. $31^{\text {st }}$ Conf. on Radar Meteor., Seattle, Amer. Meteor. Soc., 863866. [Available online at http://ams.confex.com/ ams/pdfpapers/64101.pdf.]

Rosenfeld, D., E. Amitai, and D. B. Wolff, 1995: Classification of rain regimes by the three-dimensional properties of reflectivity fields. J. Appl. Meteor., 34, 198-211.

Ryzhkov, A. V., and D. S. Zrnić, 1998: Discrimination between rain and snow with a polarimetric radar. J. Appl. Meteor., 37, 1228-1240.

Ryzhkov, A. V., and D. S. Zrnić, 2005: Radar polarimetry at S, C, and $\mathrm{X}$ bands: Comparative analysis and operational implications. Proc. $32^{\text {nd }}$ Conf. on Radar Meteor., Albequerque, NM, Amer. Meteor. Soc., 9R.3. [Available online at http://ams.confex .com/ams/pdfpapers/95684.pdf.]
Steiner, M., R. A. Houze Jr., and S. E. Yuter, 1995: Climatological characterization of three-dimensional storm structure from operational radar and rain gauge data. J. Appl. Meteor., 34, 1978-2007.

Tokay, A., D. A. Short, C. R. Williams, W. L. Ecklund, and K. S. Gage, 1999: Tropical rainfall associated with convective and stratiform clouds: Intercomparison of disdrometer and profiler measurements. J. Appl. Meteor., 38, 302-320.

Williams, C. R., W. L. Ecklund, and K. S. Gage, 1995: Classification of precipitating clouds in the tropics using $915-\mathrm{MHz}$ wind profilers. J. Atmos. Oceanic Technol., 12, 996-1012.

Zhang, C. -Z., H. Uyeda, H. Yamada, B. Geng, and Y. $\mathrm{Ni}$, 2006: Characteristics of mesoscale convective systems over the east part of continental China during the meiyu from 2001 to 2003. J. Meteor. Soc. Japan, 84, 763-782. 